\title{
Simulation Results of a Shunt Active Power Filter with Control Based on p-q Theory
}

\author{
Emílio F. Couto, Júlio S. Martins, João L. Afonso \\ Department of Industrial Electronic \\ University of Minho \\ Campus de Azurém - 4800-058 Guimarães (Portugal) \\ phone:+351253 604705, fax:+351253510189 \\ e-mail: assel.couto@clix.pt,jmartins@dei.uminho.pt,jla@dei.uminho.pt
}

\begin{abstract}
The present paper describes a shunt active power filter with a control system based on the p-q theory, and studies its performance through simulation results obtained with different types of loads.
\end{abstract}

It is explained, in a brief form, the p-q theory and its application in the control of a shunt active power filter. Matlab/Simulink was the simulation tool, used in the study, development, and performance evaluation of the shunt active power filter controller. The simulations were carried out for different loads, of linear and non-linear types.

The shunt active power filter allows compensating harmonic currents, reactive power, unbalanced loads, and zero-sequence currents, presenting a good dynamic and steady-state performance, as it can be observed in the simulation results.

\section{Key words}

Power Quality Improvement, Harmonics Compensation, Shunt Active Filter, p-q Theory, Computer Simulation.

\section{Introduction}

The intensive use of powers converters and other nonlinear loads in industry, and by consumers in general, has increased the deterioration of the power systems voltages and currents waveforms. The harmonics presence in the power lines results in varied problems, like: greater power losses in distribution; problems of electromagnetic interference in communication systems; and operation failures of protection devices, electronic equipments and, industrial processes. These problems result in high costs for industry and commercial activities, since they can lead to a decreasing in productivity and to a reduction of quality in the products or services.

Due to these problems, the quality of the electrical energy delivered to the end consumers is, more than ever, an object of great concern, being obligatory to solve the problem of the harmonics caused by "polluting" equipments (examples are: adjustable speed drivers, static converters, UPS's, PC's, and electronic equipments in general).
The passive filters have been used as a conventional solution to solve harmonic currents problems, but they present some disadvantages: they only filter the frequencies they were previously tuned for; its operation cannot be limited to a certain load or group of loads; resonance can occur due to the interaction between the passive filters and others loads, with unexpected results.

To cope with these disadvantages, recent efforts have been concentrated on the development of active power filters. In this paper the development of a shunt active filter is proposed, with a control system based on the $p-q$ theory. With this filter it is possible to effectively compensate the harmonic currents and the reactive power (correcting power factor to the unity), and also to balance the power supply currents (distributing the loads for the three-phases in equal form, and compensating zerosequence current).

\section{2. p-q Theory Description}

The p-q theory, or "Instantaneous Power Theory", was developed by Akagi et al in 1983, with the objective of applying it to the control of active power filters [1], [2]. Initially, it was developed only for three-phase systems without neutral wire, being later worked by Watanabe and Aredes [3], [4] for three-phase four wires power systems.

This theory is based on time-domain, what makes it valid for operation in steady-state or transitory regime, as well as for generic voltage and current power system waveforms, allowing to control the active power filters in real-time. Another important characteristic of this theory is the simplicity of the calculations, which involves only algebraic calculation (exception done to the need of separating the mean and alternated values of the calculated power components).

The p-q theory performs a transformation (known as "Clarke Transformation") of a stationary reference system of coordinates $a-b-c$ to a reference system of coordinates $\alpha-\beta-0$, also stationary. 


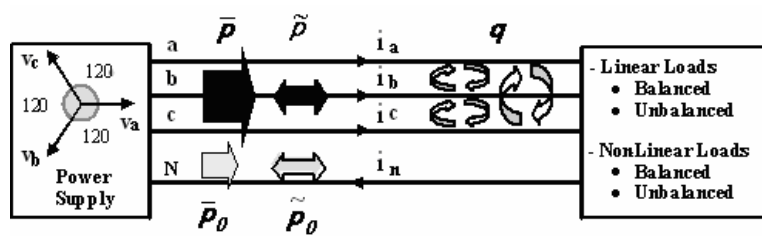

Fig. 1. p-q theory power components in a generic three-phase power system

Figure 1 allows observing the components of the $p-q$ theory in a generic power system. Each one of these power components has a meaning:

$\bar{p}$ - Medium value of the instantaneous real power It corresponds to the transferred energy per timeunit from the power source to the load, through the $a-b-c$ phases of the three-phase system.

$\tilde{p}$ - Alternated value of the instantaneous real power It corresponds to the energy per time unit that is exchanged between the power source and the load, through the $a-b-c$ phases.

$\bar{p}_{0}$ - Mean value of the instantaneous zero-sequence power - It corresponds to the transferred energy per time unit from the power source to the load, through the neutral wire and one or more phases.

$\tilde{p}_{0}$ - Alternated value of the instantaneous zerosequence power - It corresponds to the energy per time unit that is exchanged between the power source and the load, through the neutral wire and one or more phases.

$q$ - Instantaneous imaginary power

It corresponds to the power that has to circulate between the phases $a-b-c$ of the three-phase power system (it does not contribute to any transference of energy from power source to load, but produces undesirable currents).

\section{Shunt Active Filter}

From all the power components of the p-q theory, only the mean values of the instantaneous real power $(\bar{p})$ and of the instantaneous zero-sequence power $\left(\bar{p}_{0}\right)$ must come from the power supply, because them effectively transfer energy to the load.

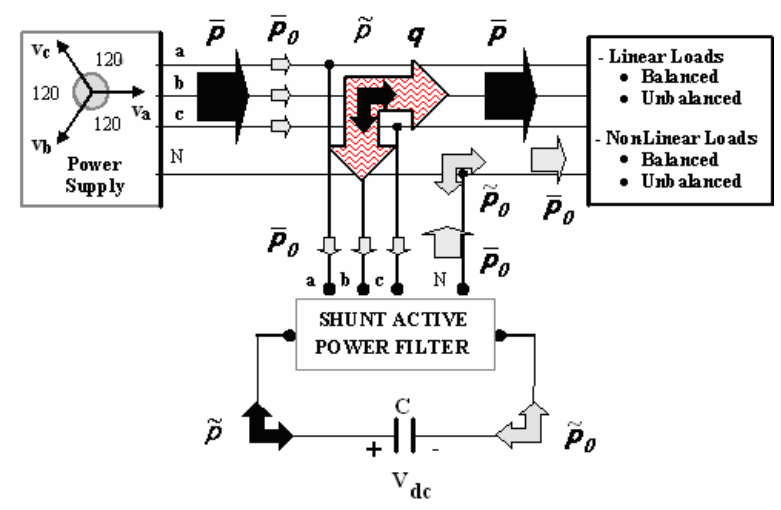

Fig. 2. p-q theory power components in a generic threephase power system with shunt active filter

The active filter also permits the power supply to deliver the value of $\bar{p}_{0}$ to the load from the phases, without the needing of the neutral wire. All the other power components $\left(\tilde{p}, \tilde{p}_{0}\right.$ and $\left.q\right)$ can be compensated with the use of the shunt active power filter, as presented in Figure 2 [5], [6].

As it is observed in Figure 3, the shunt active filter is constituted by the controller block (standard microprocessor $-\mu \mathrm{P}$ ), the inverter block (IGBT module), the DC bus (with a single capacitor), and the coupling to the power system block (with an inductance for each phase and neutral wire).

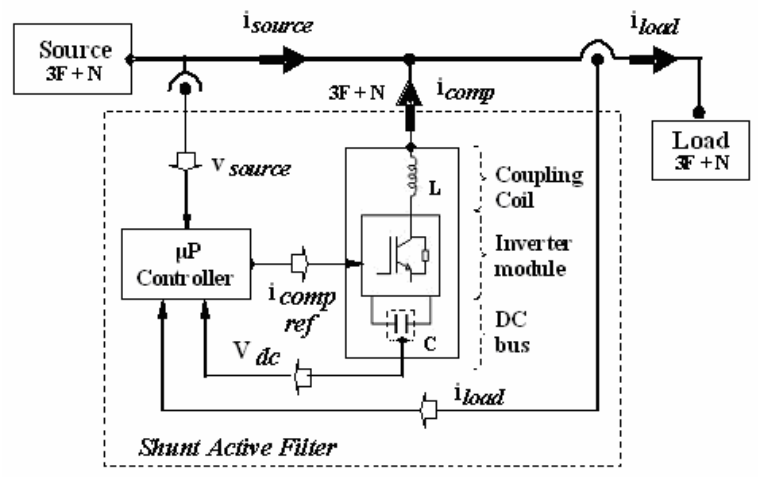

Fig. 3. The shunt active filter block diagram

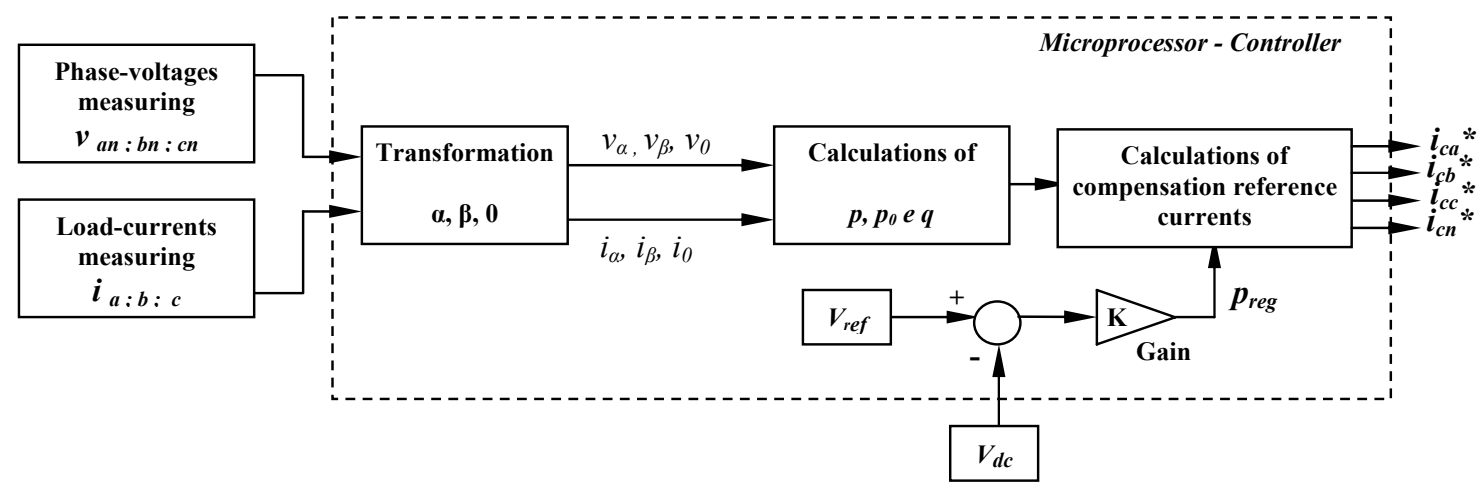

Fig. 4. Calculations of the p-q theory 


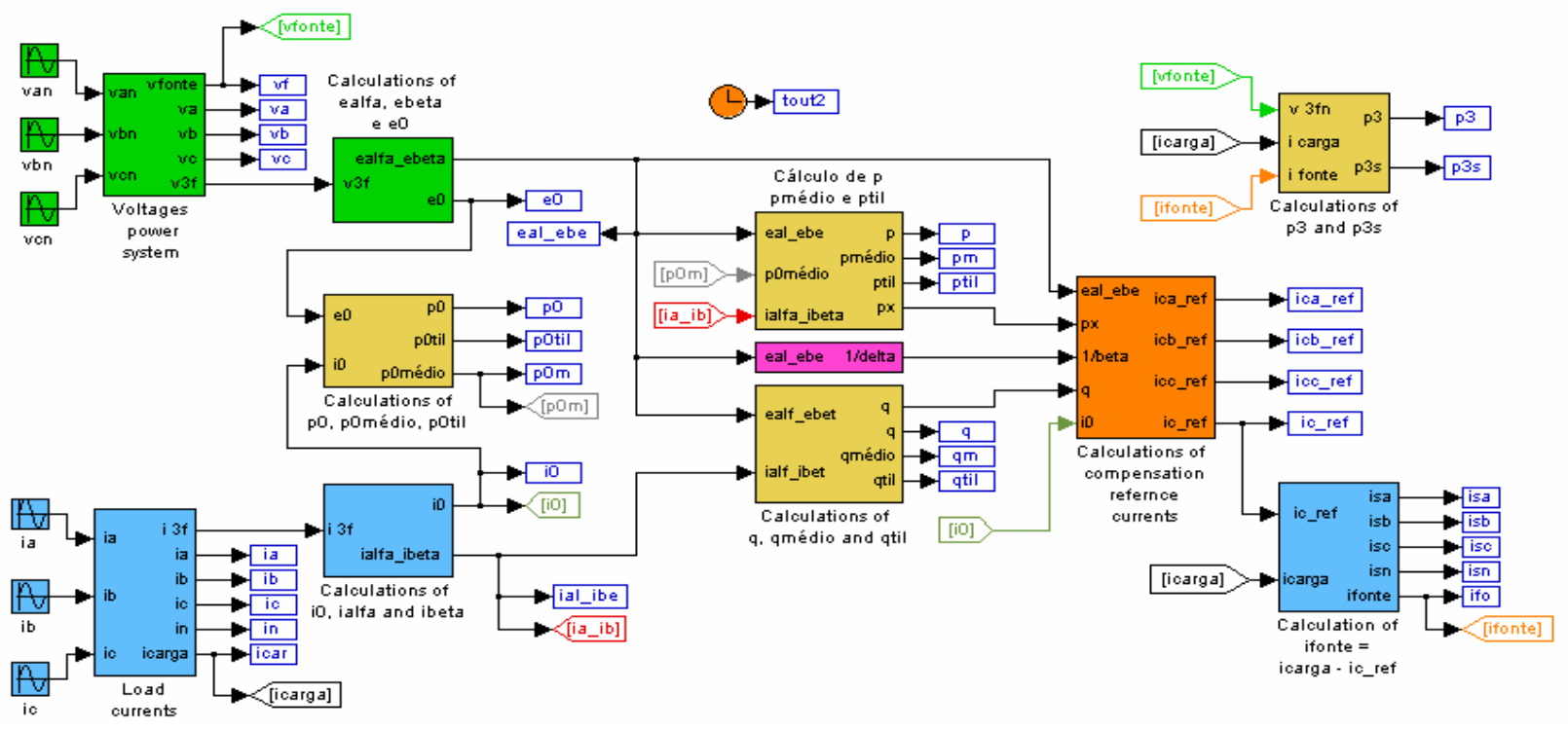

Fig. 5. Model developed in Simulink for testing the p-q theory calculations of the shunt active filter controller

The $\mathrm{p}-\mathrm{q}$ theory calculations are done in the shunt active power filter controller block. The controller allows, in a systematic way, and according to the received information, to verify the needing of compensation currents by the active filter. The controller receives the information of phase voltages, load currents and DC voltage, and based on its control algorithm, proceeds to the calculations of the $\mathrm{p}-\mathrm{q}$ theory values, generating, or not, the necessary reference compensation currents, which are injected in the power system by the inverter block (Figure 4).

The objective of this algorithm is to compensate all undesirable power components. When the power system voltages are balanced and sinusoidal (without distortion), it will lead to, simultaneously, constant instantaneous power and balanced sinusoidal currents at power supply.

Besides, the source will see the load as if it was a balanced resistive load (with unitary power factor), and the RMS value of the supply currents will be the lower possible to deliver the energy the load needs to work.

\section{Simulation Results}

The Matlab/Simulink simulation tool [7] was used to develop a model that allowed the simulation and testing of the p-q theory calculations, which were implemented in the controller of the shunt active power filter for threephase, four wire systems (Figure 5).

For the simulation of the active filter operation, with different type of loads, it was always used a balanced and sinusoidal three-phase voltages system, as can be observed in Figure 6.

The first group of loads used in the simulations analysed in this paper is presented in Figure 7. The loads in each phase are:
- phase $a$ : a typical non-linear load constituted by a single-phase rectifier with a RC load on the DC side (non-sinusoidal current waveform);

- phase $b$ : an RL linear load (sinusoidal current waveform, delayed regarding to the phase voltage);

- phase $c$ : another non-linear load, constituted by a single-phase rectifier with a RL load on the DC side (non-sinusoidal current waveform).

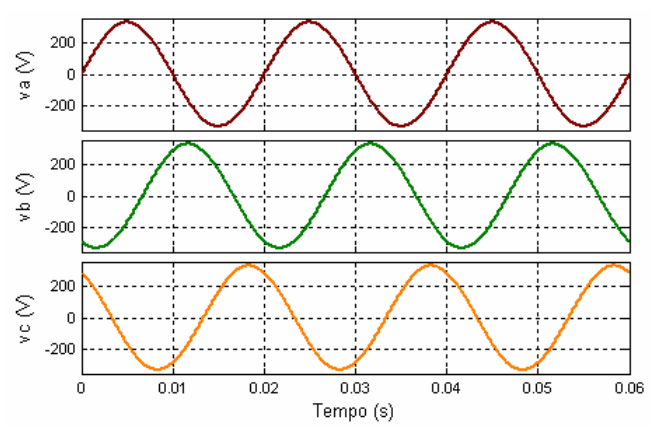

Fig. 6. Phase voltages of the simulated power system

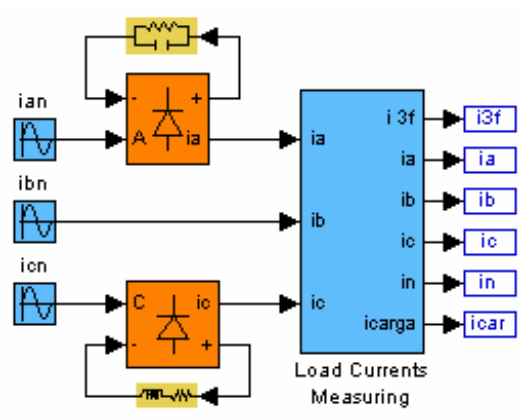

Fig. 7. The first group of loads 
First, the behaviour of the active filter is analysed in steady-state operation. Figures 8, 9 and 10 present respectively the load currents, the active filter compensation currents, and the source currents, for the 3 phases and neutral wire. It can be seen that, by action of the shunt active filter, the power supply phase currents become balanced, sinusoidal, and in phase with the phase voltages. Besides, the neutral wire current is eliminated.

It is interesting to observe that the load neutral wire current is even larger than the phase currents at load (the vertical scale of the neutral wire load current waveform is larger than the one of the load phase currents), but this current vanishes in the source, because of the active filter compensation action.

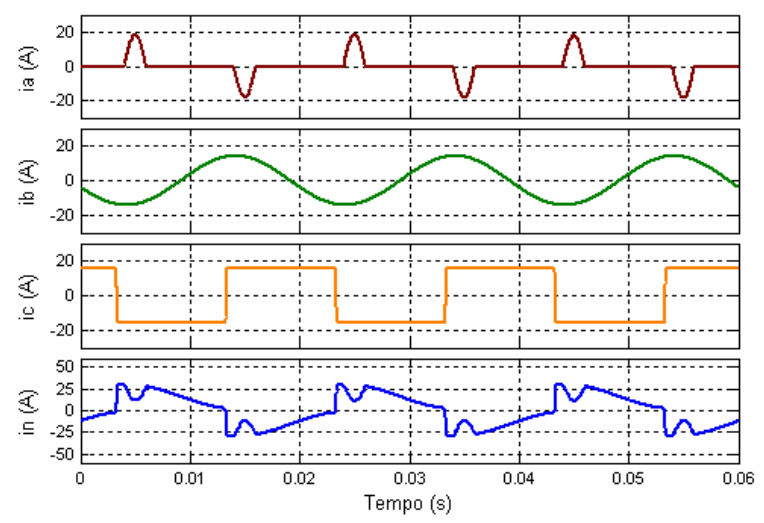

Fig. 8. Load currents waveforms

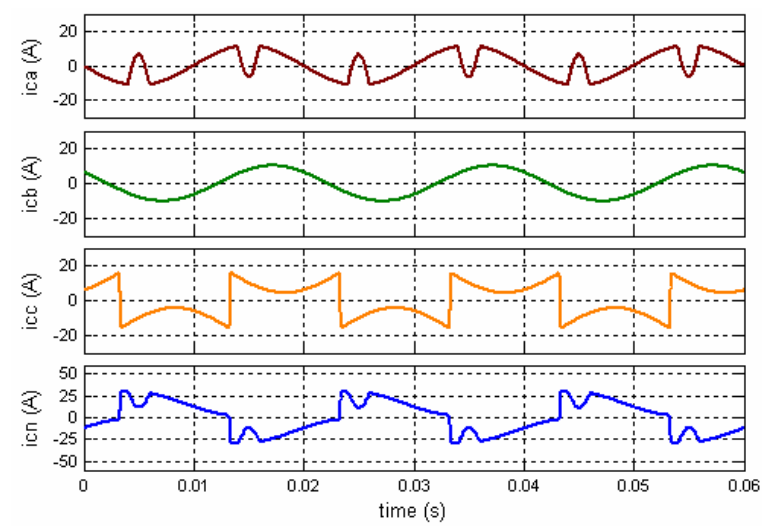

Fig. 9. Active filter compensation currents waveforms

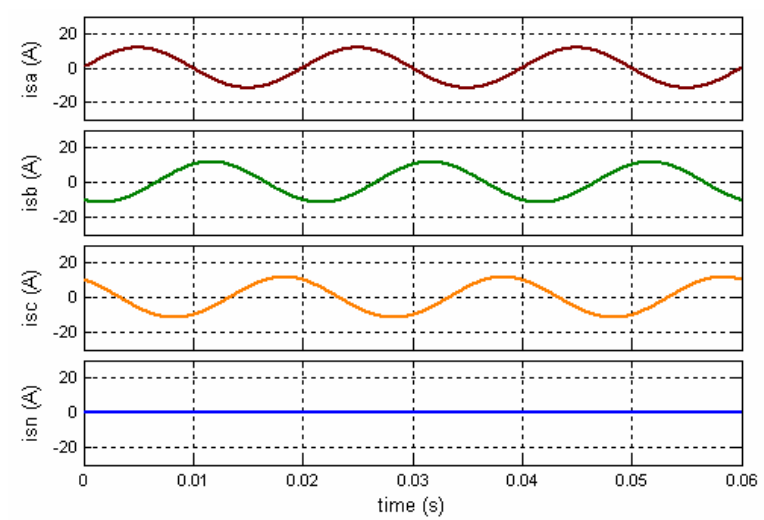

Fig. 10. Source currents waveforms
Figure 11 presents the waveform of the instantaneous three-phase power at load. It's mean value corresponds to the conventional three-phase active power, consumed by the loads of phases $a, b$ and $c$. The active filter turns the instantaneous three-phase power at source into a constant value, as can be seen in Figure 12. So, the source delivers only active power.

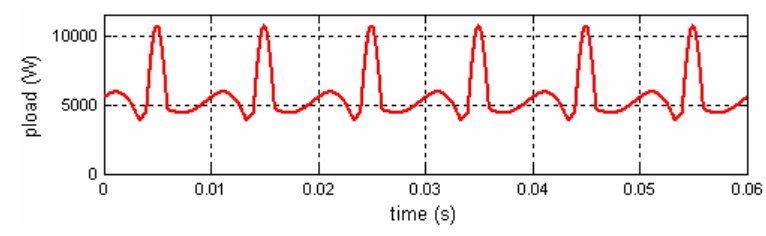

Fig. 11. Instantaneous power at load

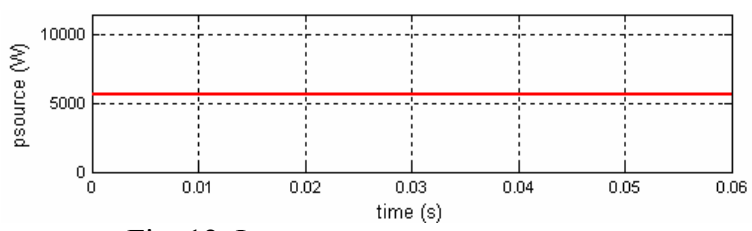

Fig. 12. Instantaneous power at source

The shunt active power filter based on the p-q theory compensates all undesirable power components, turning the power supply instantaneous three-phase power into a constant value. This constant value of power is integrally transformed in energy in the load. This way, there is no longer a power exchange between power supply and load.

Tables I and II present the values of the displacement power factor (DPF), power factor (PF), and current total harmonic distortion (THD), respectively for the load and power supply. The values of THD are showed for the phase and neutral currents. The values of DPF and PF are presented to each of the phases.

Table I - DPF, PF and currents THD values at load

\begin{tabular}{|l|c|c|c|}
\cline { 2 - 4 } \multicolumn{1}{c|}{} & \multicolumn{3}{c|}{ LOAD } \\
\cline { 2 - 4 } \multicolumn{1}{c|}{} & DPF & PF & THD (\%) \\
\hline Phase $\boldsymbol{a}$ & 1.00 & 0.564 & 146.4 \\
\hline Phase $\boldsymbol{b}$ & 0.707 & 0.707 & 0 \\
\hline Phase $\boldsymbol{c}$ & 1.00 & 0.905 & 47.1 \\
\hline neutral & - & - & 38.3 \\
\hline
\end{tabular}

Table II - DPF, PF and currents THD values at source

\begin{tabular}{|l|c|c|c|}
\cline { 2 - 4 } \multicolumn{1}{c|}{} & \multicolumn{3}{c|}{ SOURCE } \\
\cline { 2 - 4 } \multicolumn{1}{c|}{} & DPF & PF & THD (\%) \\
\hline Phase $\boldsymbol{a}$ & 1.00 & 1.00 & 0 \\
\hline Phase $\boldsymbol{b}$ & 1.00 & 1.00 & 0 \\
\hline Phase $\boldsymbol{c}$ & 1.00 & 1.00 & 0 \\
\hline
\end{tabular}

Comparing these two tables it is confirmed that the shunt active filter can compensate the power factor and the harmonic currents, turning then respectively into one and zero at power supply. 
Figure 13 presents the second group of loads used in the simulation and analysis. These loads are of the same type of the ones in the first group, however they have a transition block, which allows varying their values of currents at a certain specified time. It permits the study of the active filter control system under transient conditions. The transition block acts at the time instant $\mathrm{t}=30 \mathrm{~ms}$, modifying the loads currents: it doubles the amplitude values of the currents in phases $a$ and $c$, and turns-off the load in phase $b$.

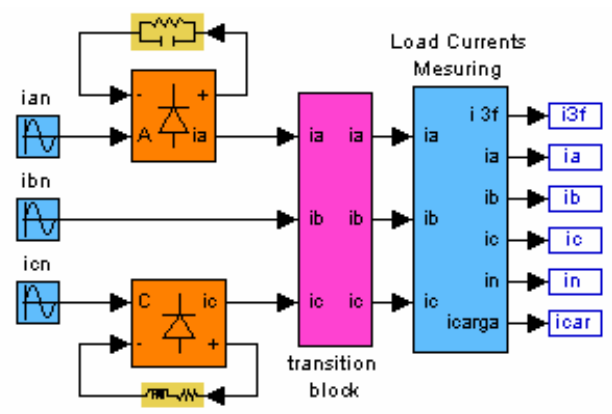

Fig. 13. The second group of loads

Figures 14, 15 and 16 present respectively the load currents, the active filter compensation currents, and the source currents, for the 3 phases and neutral wire, during $30 \mathrm{~ms}$ before and $50 \mathrm{~ms}$ after the action of the transition block.

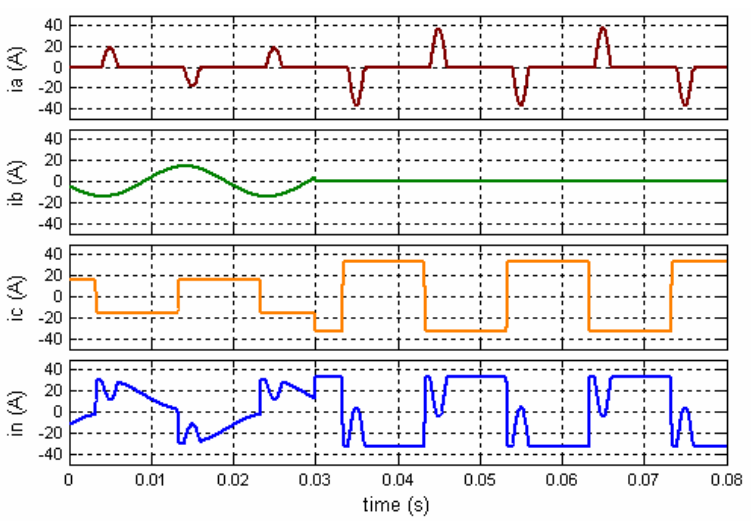

Fig. 14. Load currents waveforms

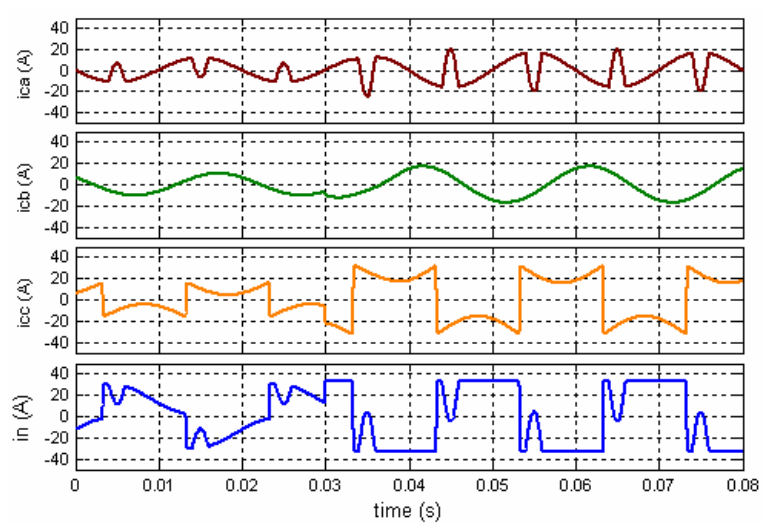

Fig. 15. Active filter compensation currents waveforms

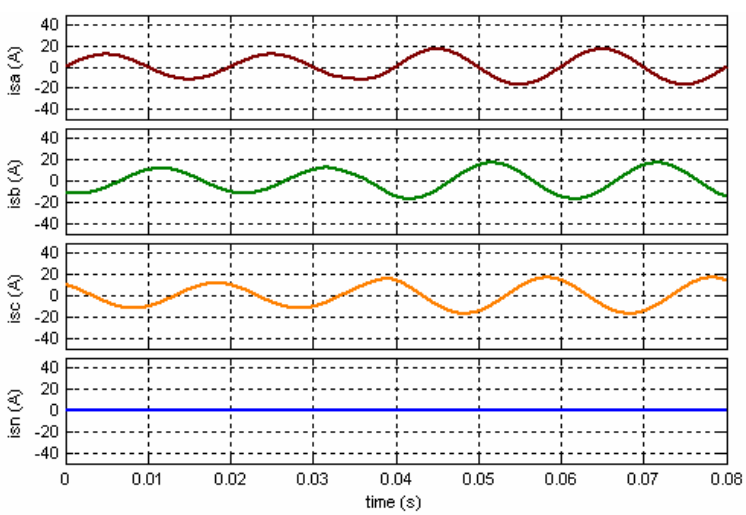

Fig. 16 - Source currents waveforms

Observing these 3 figures it is possible to conclude that the controller based on the p-q theory presents a good transitory behaviour. It is interesting to notice that the neutral current at power source is kept null even during the changing of the loads currents.

Figure 17 presents the waveform of the instantaneous three-phase power at load before and after the load currents changing. Figure 18 shows the three-phase instantaneous power at source. It can be seen that the source power has a constant value before the loads changing, and assumes a new constant value $10 \mathrm{~ms}$ after the changing. This time interval (half cycle of the power system frequency period) depends exclusively on the time the control algorithm needs to calculate the new value of $\bar{p}$, obtained with the new load conditions.

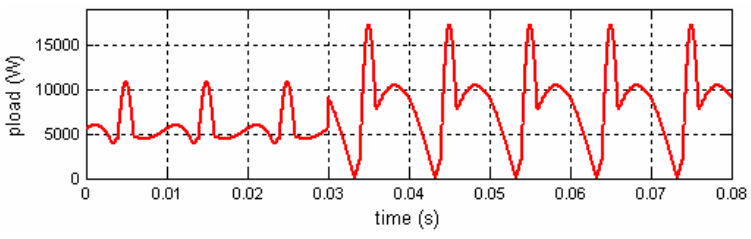

Fig. 17. Instantaneous power at load

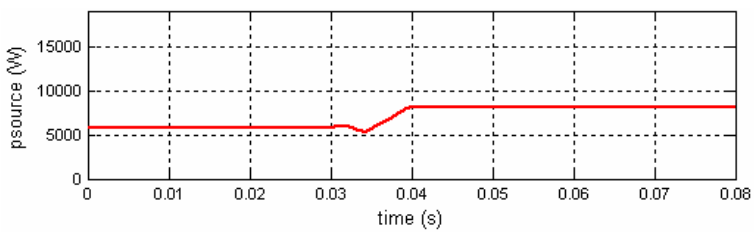

Fig. 18. Instantaneous power at source

Tables III and IV present the values DPF, PF and THD, respectively for the load and power supply. The values of THD are showed to the phase and neutral currents. The values of DPF and PF are presented to each of the phases. These tables refer to the new load values obtained after the operation of the transition block. 
Table III - DPF, PF and currents THD values at load

\begin{tabular}{|l|c|c|c|}
\cline { 2 - 4 } \multicolumn{1}{c|}{} & \multicolumn{3}{c|}{ LOAD } \\
\cline { 2 - 4 } \multicolumn{1}{c|}{} & DPF & PF & THD (\%) \\
\hline Phase $\boldsymbol{a}$ & 1.00 & 0.564 & 146.4 \\
\hline Phase $\boldsymbol{b}$ & - & - & - \\
\hline Phase $\boldsymbol{c}$ & 1.00 & 0.905 & 47.1 \\
\hline neutral & - & - & 49.2 \\
\hline
\end{tabular}

Table IV - DPF, PF and currents THD values at source

\begin{tabular}{|l|c|c|c|}
\cline { 2 - 4 } \multicolumn{1}{c|}{} & \multicolumn{3}{c|}{ SOURCE } \\
\cline { 2 - 4 } \multicolumn{1}{c|}{} & DPF & PF & THD (\%) \\
\hline Phase $\boldsymbol{a}$ & 1.00 & 1.00 & 0 \\
\hline Phase $\boldsymbol{b}$ & 1.00 & 1.00 & 0 \\
\hline Phase $\boldsymbol{c}$ & 1.00 & 1.00 & 0 \\
\hline
\end{tabular}

Once more it is confirmed that the shunt active filter can compensate the power factor and the harmonic currents.

\section{Conclusion}

In this paper, it is shown through computer simulations, using Matlab/Simulink, that the p-q theory can be used with success in the implementation of shunt active power filters controllers. The following conclusions could be achieved regarding the studied active filter and its control system:

- It compensates dynamically the harmonic currents;

- It corrects dynamically the power factor;

- It compensates dynamically, and instantaneously, the zero-sequence current;

- It balances and reduces the values of the currents supplied by the source to the load;

- It turns the instantaneous three-phase power that source delivers to load into a constant value (the source only delivers conventional active power).
The active filter controller based on the $\mathrm{p}-\mathrm{q}$ theory was tested for three-phase power systems with neutral wire, with linear and non-linear, and unbalanced loads.

The obtained results show good steady-state and transitory performances.

\section{References}

[1] H. Akagi, Y. Kanazawa, A. Nabae, "Generalized Theory of the Instantaneous Reactive Power in ThreePhase Circuits", IPEC'83 - Int. Power Electronics Conf., Tokyo, Japan, 1983, pp. 1375-1386.

[2] H. Akagi Y. Kanazawa, A. Nabae, "Instantaneous Reactive Power Compensator Comprising Switching Devices without Energy Storage Components", IEEE Trans. Industry Applic., vol. 20, May/June 1984.

[3] E. H. Watanabe, R. M. Stephan, M. Aredes, "New Concepts of Instantaneous Active and Reactive Powers in Electrical Systems with Generic Loads", IEEE Trans. Power Delivery, vol. 8, no. 2, April 1993, pp. 697-703.

[4] M. Aredes, E. H. Watanabe, "New Control Algorithms for Series and Shunt Three-Phase FourWire Active Power Filters", IEEE Trans. Power Delivery, vol 10, no. 3, July 1995, pp. 1649-1656.

[5] J. L. Afonso, C. Couto, J. S. Martins, “Active Filters with Control Based on the p-q Theory", IEEE Industrial Electronics Society Newsletter, vol. 47, $\mathrm{n}^{\mathrm{o}}$ 3, Set. 2000, pp. 5-10.

[6] J. L. Afonso, H. R. Silva, J. S. Martins, "Active Filters for Power Quality Improvement”, IEEE Power Tech'2001, Porto, Portugal, 10-13 Set. 2001.

[7] Simulink - Model-Based and System-Based Design, Modelling, Simulation, Implementation, version 5, The MathWorks, July 2002. 